\title{
Investigation of dairy cattle ease of movement on new methyl methacrylate resin aggregate floorings
}

\author{
N. Franco-Gendron, ${ }^{*}$ R. Bergeron, ${ }^{*}$ W. Curilla, $†$ S. Conte, $\ddagger$ T. DeVries, ${ }^{*}$ and E. Vasseur ${ }^{1}$ \\ *Department of Animal Biosciences, University of Guelph, Guelph, Ontario, N1G 2W1, Canada \\ †SureBond Safe Floors (formerly AB Silikal Hygienic Floors), a div. of Diamond Hard Surfaces (Calgary) Inc., Calgary, Alberta, T2A 6R3, Canada \\ $\ddagger$ Agriculture and Agri-Food Canada, Sherbrooke Research and Development Centre, Sherbrooke, Quebec J1M 0C8, Canada \\ §Department of Animal Science, McGill University, Ste-Anne-de-Bellevue, Quebec, H9X 3V9, Canada
}

\begin{abstract}
Freestall dairy farms commonly present issues with cattle slips and falls caused by smooth flooring and manure slurry. This study examined the effect of 4 new methyl methacrylate (MMA) resin aggregate flooring types (1-4) compared with rubber (positive) and concrete (negative control) on dairy cow $(\mathrm{n}=18)$ ease of movement when walking on straight and right-angled corridors. Our hypothesis was that cow ease of movement when walking on the MMA surfaces would be better than when walking on traction milled concrete, and at least as good as when walking on rubber. Cattle ease of movement was measured using kinematics, accelerometers, and visual observation of gait and associated behaviors. Stride length, swing time, stance time, and hoof height were obtained from kinematic evaluation. Acceleration and asymmetry of variance were measured with accelerometers. Locomotion score and behaviors associated with lameness, such as arch back, head bob, tracking up, step asymmetry, and reluctance to bear weight were visually observed. Stride length, swing time, stance time, and the number of steps taken were the only variables affected by flooring type. Differences between flooring types for these variables were tested using a generalized linear mixed model with cow as a random effect, week as a random block factor, and flooring type as a fixed effect. Multiple comparisons with a Scheffé adjustment were done to analyze differences among flooring types. Stride length was 0.14 $\mathrm{m}$ longer (better) on rubber when compared with concrete, and 0.11 and $0.17 \mathrm{~m}$ shorter on MMA 1 and 2 compared with rubber. On MMA 3 and 4, stride length did not differ from either rubber or concrete. Swing time was $0.04 \mathrm{~s}$ shorter (worse) on MMA 1 than on rubber, but did not differ from any other flooring. Stance
\end{abstract}

Received March 2, 2016

Accepted July 3, 2016.

${ }^{1}$ Corresponding author: elsa.vasseur@mcgill.ca time was $0.18 \mathrm{~s}$ longer (worse) on MMA 2 when compared with rubber, but it did not differ from any other treatment. The number of steps was higher on MMA 4 compared with rubber (4.57 vs. 3.95 steps), but did not differ from any other treatment. Of all the MMA floors tested, MMA 3 was the only one that was consistently as good as rubber (positive control). All 4 MMA floors never differed from concrete (negative control) in any of the ease of movement variables measured. These results suggest that MMA 3 may improve cow ease of movement, compared with the other MMA floors, but more research is required to confirm these findings.

Key words: flooring type, methyl methacrylate resin aggregate, ease of movement, dairy cow

\section{INTRODUCTION}

Lameness is a major concern in dairy cattle, affecting between 25 and $29 \%$ of animals in freestall facilities (Espejo et al., 2006; Ito et al., 2010). Lameness is known to be a painful condition that affects animal welfare and causes significant economic losses for producers (Warnick et al., 2001; Vermunt, 2007). It is the second most costly health condition, following mastitis (Kossaibati and Esslemont, 1997; Greenough and Weaver, 1997; Cha et al., 2010). Cows that are lame have a tendency for a reduction in milk yield (Cha et al., 2010), a lower BCS (Peake et al., 2011), and impaired reproductive abilities (Weber et al., 2013). Lameness also increases the culling rate of the herd (Enting et al., 1997), which will in turn decrease its longevity (Booth et al., 2004).

Many environmental factors can have an effect on the incidence of lameness on farms. Possible risk factors include stall comfort and dimensions (Charlton et al., 2016), bedding type (Chapinal et al., 2013a), infrequent exercise (Popescu et al., 2013), and flooring type (Cook et al., 2004; Rushen and de Passillé, 2006). Several types of flooring are available on farm, but identifying the best options may be very complex. It is important that the flooring installed brings comfort as well as traction, to ensure that it does not compromise 
cattle ease of movement or inflict hoof or limb issues (Rushen and de Passillé, 2009). The most common type of flooring found on Canadian freestall dairies is concrete (Solano et al., 2015). However, rubber has become an increasingly popular alternative over the last $20 \mathrm{yr}$ (USDA, 2009).

Increasing floor friction may result in a reduction in slips and falls (Phillips and Morris, 2001). Clean and dry floors will also help reduce slipperiness and potential leg injuries resulting from falls (Phillips and Morris, 2001). Floor cleanliness is also essential to minimize claw health issues and reduce the transmission of infectious diseases (Hinterhofer et al., 2006).

Both rubber and concrete, when covered in manure slurry or not properly scraped, may become slippery, which may increase the risk of slips and falls and cause injuries (Phillips and Morris, 2001; Rushen and de Passillé, 2006). Furthermore, when the hooves of cattle are constantly exposed to moisture and manure, this causes the hooves to become soft, which may result in heel or sole crack, and further degrade into ulcers, abscesses, or other hoof infections (Ishler et al., 1999). Slippery floors may also alter cattle ease of movement (Flower et al., 2005, 2007; Flower and Weary, 2006; Flower and Weary, 2009), making it more difficult for cattle to move around within their facility (Philips et al., 2013). Kinematic variables such as stride length, swing time, stance time, and hoof height may differ when healthy or compromised cattle walk on either rubber or concrete flooring (Flower et al., 2005, 2007; Blackie et al., 2013). These measures may thus indicate whether or not a surface is adequate for cattle to walk on. Furthermore, inadequate flooring may reduce walking speed and negatively affect locomotion scores and behaviors associated with lameness (Telezhenko and Bergsten, 2005; Flower et al., 2007; Chapinal et al., 2011). Adding small particles (aggregates) that adhere to the floor surface provides animals with better traction due to an increased coefficient of friction, and can improve stride length, speed, swing time, stance time, and overall cattle locomotion (Phillips and Morris, 2001; Rushen and de Passillé, 2006). Consequently, having a flooring that provides better traction even when wet could improve cattle ease of movement, which may decrease the incidence of slips and falls hence reduce lameness cases on farms.

The purpose of the study was to investigate cattle ease of movement on 4 new types of methyl methacrylate (MMA) floorings to see how they would compare with a positive and a negative control flooring. Rubber was chosen as the positive control because it is a more compressible surface (Rushen and de Passillé, 2006), which brings more comfort to cattle by reducing pressure on the limbs and joints (van der Tol et al., 2005;
Hernandez-Mendo et al., 2007). Concrete, on the other hand, is a harder surface with little compressibility (Rushen and de Passillé, 2006), and thus was considered as a negative control. However, depending on its finish, concrete may offer more friction than rubber, which may decrease the incidence of slips on wet flooring (Telezhenko and Bergsten, 2005). Our hypothesis was that cow ease of movement when walking on the MMA surfaces would be better than when walking on traction milled concrete as concrete is known to be a more slippery surface when wet. Yet, we hypothesize that the ease of movement of cattle walking on the MMA surface will be at least as good as when walking on rubber because the MMA surface provides more friction then rubber.

\section{MATERIALS AND METHODS}

\section{Animals}

A total of 18 Holstein cows were selected from the Organic Dairy Research Farm at the University of Guelph-Alfred Campus (Alfred, Ontario, Canada). The cows were housed in a freestall facility and were cared for according to the standards and guidelines of the Canadian Council on Animal Care (2009). The experimental protocol was approved by the University of Guelph Animal Care Committee. Only sound and healthy animals were enrolled in the study. The 2 most recent hoof trimming reports (2 and 9 mo before the study) were consulted to select cows without any hoof disease or hoof injury, and a visual gait scoring was done by one trained observer while cows were walking on a sand path to ensure none were clinically lame [none with a numerical rating system (NRS) $\geq 4$ as described by Flower and Weary (2006)]. The selected cows had a parity range of 1 to 6 (parity $1: \mathrm{n}=6$ cows; parity 2 : $\mathrm{n}=5$; parity $3: \mathrm{n}=3$; parity $\geq 4: \mathrm{n}=4$ ) to maximize the chance that cows had different gait scores because parity influences gait as observed by Chapinal et al. (2009). The experimental cows were all $\geq 122$ DIM (mid lactation: 122-198 DIM, $\mathrm{n}=6$ cows; late lactation: 208-291 DIM, $\mathrm{n}=7$; and dry $\geq 305$ DIM $\mathrm{n}=5$ ) at the beginning of the trial.

\section{Flooring Types}

Two control flooring types, rubber mats, $1.9 \mathrm{~cm}$ thick (Animat Inc., Saint-Élie d'Orford, QC, Canada), and traction milled concrete (Agri-Trac, Woodstock, ON, Canada) were chosen, as they are the common types of flooring found in dairies in North America (concrete found mostly in parlors at $67 \%$, holding pens at $65 \%$, and rubber found in parlors at $33 \%$, holding pens at 
Table 1. Dynamic coefficient of friction (DCOF) reported in literature for rubber mats and concrete or measured in laboratory for MMA 1 to 4

\begin{tabular}{lllll}
\hline Flooring type & DCOF & Test method & Surface condition & Reference \\
\hline Rubber mats $^{1}$ & 0.48 & Tribometer, 100 kg weight & Dry & Penev et al., 2013 \\
& 0.47 & Standard ASTM D1894 & Dry & Rushen and de Passillé, 2006 \\
& 0.46 & Portable friction tester & Manure slurry & Telezhenko and Bergsten, 2005 \\
Concrete $^{1}$ & 0.58 & Portable friction tester & Manure slurry & Telezhenko and Bergsten, 2005 \\
& 0.43 & Tribometer, 150 kg weight & Dry & Phillips and Morris, 2000 \\
MMA 1 & 0.30 to 0.45 & Skid resistance tester & Wet & Georg, 2011 \\
MMA 2 & 0.70 & ANSI B101.3 rubber foot & Wet & SureBond Safe Floors \\
MMA 3 & 0.67 & ANSI B101.3 rubber foot & Wet & SureBond Safe Floors \\
MMA $4^{2}$ & 0.66 & ANSI B101.3 rubber foot & Wet & SureBond Safe Floors $^{3}$ \\
\hline
\end{tabular}

${ }^{1}$ Friction coefficients reported by other researchers.

${ }^{2}$ Friction coefficients obtained from supplier.

${ }^{3}$ SureBond Safe Floors, Calgary, Alberta, Canada.

27\%; USDA, 2009; Solano et al., 2015). These controls were compared with 4 concrete-based aggregated MMA coated floorings with high degrees of friction: MMA 1 (0.7-1.2 mm quartz, 1 seal coat), MMA 2 (0.7-1.2 mm quartz, 2 seal coats), MMA 3 (0.4-0.8 mm quartz, 1 seal coat), and MMA $4(0.4-0.8 \mathrm{~mm}$ quartz, 2 seal coats; SureBond Safe Floors, Calgary, AB, Canada). The dynamic coefficients of friction provided by the manufacturer decreased from MMA 1 to 4 and were all higher than the coefficients of friction reported in the literature for the 2 controls (Table 1). The size of the quartz and number of seal coats added on the MMA surfaces influenced the coefficient of friction of the floors as seen in Table 1. Greater particle size gave the flooring more texture, which resulted in a higher friction (Table 1). However, the seal coat, added to the MMA surface for flooring protection and durability, made the surface smoother, which slightly decreased the friction (Table 1).

\section{Flooring Configurations}

Test corridors were built with concrete paving slabs $(61 \times 61 \mathrm{~cm})$, which were either traction milled or covered with the various MMA resin aggregate surfaces. The lines of the traction milled concrete blocks were placed parallel to the direction the cows were walking. Rubber mats were laid directly on the floor of the test arena. Each block or rubber mat was tightly placed next to each other, forming gap-free corridors. Two corridor configurations were tested for each flooring type: straight $(1.2 \mathrm{~m}$ wide $\times 9.1 \mathrm{~m}$ long $)$ and right angled with a $90^{\circ}$ angle $(1.2 \times 5.5 \mathrm{~m}$ entering and $1.8 \times 4.9$ $\mathrm{m}$ in the angle; Figure 1). Two corridors (corridor 1 and 2) were installed side by side, allowing tests on 2 different flooring types each day (Figure 1). Corridors were outlined with fencing tape (12.5 mm Turbo Tape, Gallagher, Owen Sound, ON, Canada) and pigtail fence posts (Gallagher, Owen Sound, ON, Canada) fixed in buckets filled with sand.

\section{Training and Tests}

Three training groups (6 cows per group) were formed to facilitate the habituation period. Each group were taken from the barn after the morning milking (0800 h) once a week and were led to the experimental building, enticed with grain buckets. Cows were individually trained by walking 5 times on each flooring and configuration, whereas the 5 other cows were kept in a waiting pen within visual and auditory range (Figure $1)$. The selected training group were randomly introduced to 2 new flooring types per week during a 3 -wk habituation period. They walked on both corridors in straight configuration on wk 1 , on both corridors in a right-angled configuration on wk 2 , and on both corridors in the 2 configurations on wk 3 . By the end of the training period, the cows walked on all flooring types in both configurations. Once trained, cows were randomly reallocated to groups of 6 individuals, which were changed every week to ensure there were no influences of groups on cow behavior.

Due to space and time constraints, only 2 flooring types in both configurations were tested each day. Tests were done on Mondays, Wednesdays, and Fridays to allow for flooring reconfiguration between test days. All 6 floorings were tested each week in a randomized order. A new group of 6 cows was tested on each of the $3 d$, and the 18 cows were tested each week on a maximum of one flooring type. Therefore, $6 \mathrm{wk}$ were necessary to test all cows on each flooring type.

Cows walked on the same flooring type for at least 5 walking passages in each configuration (10 passages/ cow per d), to ensure that at least one passage with a steady pace could be obtained. Passages where cows ran, defecated, or stopped were not used for analy- 
sis. When cows defecated on the corridor, the excess manure was removed to ensure that only a thin coat remained on the floor. Cows were lured by a handler walking backward at a distance of approximately $1 \mathrm{~m}$ in front of them and holding a bucket of grain. Another handler also walked to the side of the cows, behind the point of balance (Grandin, 2010), and tapped the floor in a rhythmic manner with a stick to encourage walking. The handler located next to the cows would never touch them while walking, but would gently pat the cows with their hand if they stopped.

Each day, once corridor configurations were set up, and before tests were started, flooring surfaces were covered with a thin coat of manure slurry (equal volumes of manure and water) using a paint roller. Once the cows were done walking on the straight corridor or right-angled turn corridor, cows were sent outside on pasture with access to water and shade, giving the handlers time to change corridor configurations.

\section{Acceleration}

Every test day immediately before walking, cows were equipped with two 3-D accelerometers (Hobo Pendant

\section{A - Straight Configuration}

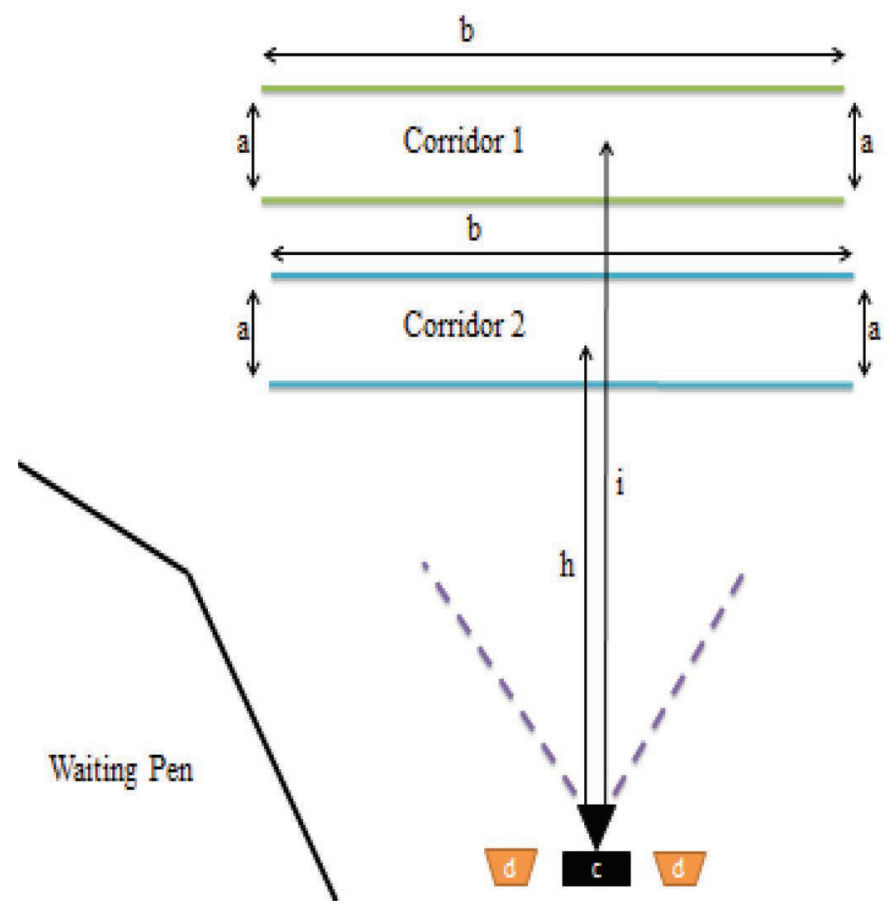

G Acceleration Data Logger, Onset Computer Corp., Bourne, MA), which were placed in custom-made pouches attached with Velcro to both rear legs above the fetlock. The accelerometers were set to sample 33 readings/s (de Passillé et al., 2010; Chapinal et al., 2011). The time clocks on the video camera and the accelerometers were synchronized to be able to match data recorded by both devices. Acceleration was measured as the rate of change of velocity across rear limbs for a particular passage per unit of time (Chapinal et al., 2011). The overall acceleration was calculated for the 3 axes as the magnitude of the 3 -D acceleration vector for each limb using the following formula (Chapinal et al., 2011):

$$
\text { acceleration }(g)=\sqrt{\operatorname{acc}_{x}^{2}+\operatorname{acc}_{y}^{2}+\operatorname{acc}_{z}^{2},}
$$

where the $\operatorname{acc}_{x}$ is the acceleration for the $\mathrm{x}$-axis, $\operatorname{acc}_{y}$ is the acceleration for the $\mathrm{y}$-axis, and $\mathrm{acc}_{z}$ is the acceleration for the z-axis. To find the mean acceleration for each limb, the acceleration was averaged, and the variance was calculated over a selected passage time based on the calculated vector. The acceleration and

\section{B - Right Angle Configuration}

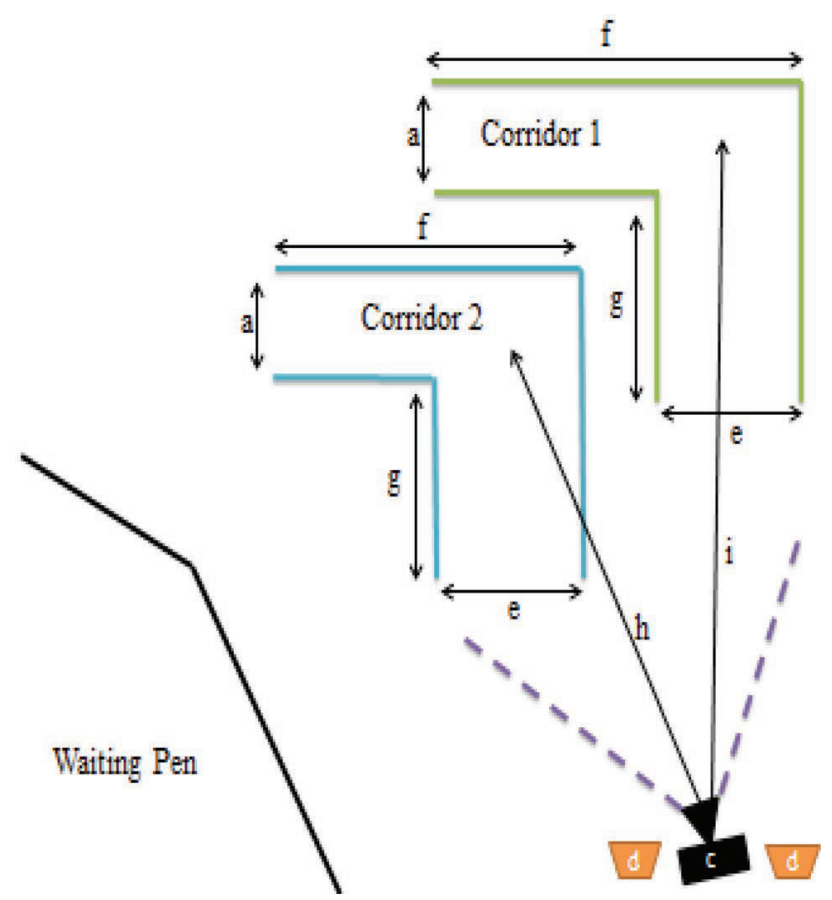

Figure 1. Corridors and flooring configurations [straight (A) and right angle (B)] showing the waiting pen, corridor, camera, and spotlight placement. Distance a is equal to $1.21 \mathrm{~m}$, b is $9.14 \mathrm{~m}$, c is the camera, d are the spotlights, e is $1.82 \mathrm{~m}, \mathrm{f}$ is $5.48 \mathrm{~m}, \mathrm{~g}$ is $4.88 \mathrm{~m}, \mathrm{~h}$ is $9.65 \mathrm{~m}$, and $\mathrm{i}$ is $11.80 \mathrm{~m}$. Color version available online. 
variances for each limb were averaged together resulting in a single mean and variance of acceleration for the selected passage per flooring type. From the calculated variances per limb, the asymmetry of variance (\%) was obtained using the formula (Chapinal et al., 2011):

$$
\begin{aligned}
& \text { asymmetry of variance }(\%) \\
& =\left[1-\left(\frac{\text { variance }_{\min }}{\text { variance }_{\max }}\right)\right] \times 100,
\end{aligned}
$$

where the variance $_{\min }$ was the lowest variance of acceleration and variance $_{\max }$ was the highest variance within each pair of limbs. The asymmetry of variance calculated for the rear limbs was averaged across passages to get a single asymmetry of variance value for each cow per flooring type (Chapinal et al., 2011). The asymmetry of variance represents how irregular the stepping patterns were for both rear limbs based on the accelerometer (Chapinal et al., 2011).

\section{Steps Taken and Passage Time}

Cows were video recorded on the right side while walking in the right-angled corridors. The camcorder (JVC AVCHD 40X Optical Zoom, Konica Minolta HD Lens 116mm 1:1.8, Mississauga, ON, Canada) was placed diagonally from the first straight section of each corridor at a distance of 11.8 and $9.7 \mathrm{~m}$ from corridor 1 and 2 (Figure 1). The same method as in the straight corridor configuration was used to encourage cows to walk. A total of 108 video recordings were analyzed for the number of steps taken, passage time (s), and time per step (s/step) for a chosen passage of each cow walking on all flooring types. Passage time refers to the amount of time taken to complete a passage, the steps taken refers to the number of steps taken to complete a passage, and the time per step is the amount of time elapsed between each step or stride. Count started when the hind right hoof stepped on the tested flooring and ended when it left the flooring at the end of the passage. Passage time was calculated from the same start and finish points as those used to count the number of steps. Time taken per step was obtained by dividing passage time by number of steps.

\section{Kinematics}

Kinematic measurements were only taken in the straight configuration. Cows were filmed on their right side following Flower et al. (2007) and Grégoire et al. (2013). Two reflective plastic ball markers measuring $3.18 \mathrm{~cm}$ (B \& L Engineering, Santa Ana, CA) were sewn on a 12-cm-wide black elastic band, adjustable with Velcro, and long enough to be placed on the metatarsal and metacarpal regions of the right limbs before the cows walked on each corridor. Two reflective plastic balls were also placed on the floor $(8.57$ $\mathrm{m}$ apart) as reference markers. A digital video camera (uEye UI-1225LE-C, Imaging Development Systems GmbH, Obersulm, Germany) with lens (Pentax CCTV C418DX, 4.8 mm, 1:1.8, Pentax Ricoh Imaging Americas Corporation, Denver, CO) was used to video record the right side of the cows while walking. Two spotlights (Pro light w/Lamp P2-101, 250 W, Lowel, Hauppauge, $\mathrm{NY}$ ) were placed $0.5 \mathrm{~m}$ away from both sides of the camera to light up the reflective markers. The camera was placed perpendicular to the center of the corridors (9.7 m away from corridor 1 and $11.8 \mathrm{~m}$ from corridor 2 ; Figure 1). The walking passages of the cows were recorded and digitalized for 3 or 4 strides at 30 frames/s. A total of 108 video recordings were then analyzed using an automatic tracking program (MoviAs Pro, version 1.63g: 3D, NAC Image Technology, Simi Valley, $\mathrm{CA})$. Once the recordings were processed, the stride length $(\mathrm{m})$, swing time $(\mathrm{s})$, stance time $(\mathrm{s})$, and hoof height $(\mathrm{m})$ were calculated for both the front and rear right hoof. Stride length corresponds to the distance between 2 consecutive hoof strikes for the same hoof. Swing time and stance time refer to the periods of time when a cow's hoof is respectively off and on the ground during a stride, and hoof height refers to the maximal vertical distance at which the hoof is lifted while the cow is walking (Flower et al., 2005, 2007). The mean and standard error for stride 2 and 3 were calculated for each variable.

\section{Gait Scoring and Behaviors Associated with Lameness}

The videos used for the kinematic analysis were also used to evaluate the gait of the cows while walking on different flooring types in the straight corridors. Scoring was done by one observer, previously trained by scoring video recordings of cows that had been scored beforehand by an expert. The flooring types were coded with numbers so that the observer was unaware of experimental treatments. Cow gait was scored using the NRS procedure, as described by Flower and Weary (2009) (1 to 5 scale where 1 is sound and 5 is severely lame, scored at 0.5 intervals) and 6 behaviors associated with lameness: arch back, head bob, tracking up, joint flexion, asymmetric steps, and reluctance to bear weight ( 0 to 5 scale where 0 is sound and $5 \mathrm{bad}$, scored at 0.1 intervals) as defined by Flower and Weary (2006). The outcomes of each variable were recorded 
by averaging the scores obtained using a visual analog scale template developed in Microsoft Excel (Microsoft Corp., Redmond, WA). The training process took $1 \mathrm{wk}$ and the observer started scoring the video recordings once a target level of agreement of $90 \%$ for intra- and inter-observer reliability was reached for the NRS scoring, and $80 \%$ for the behaviors associated with lameness. A total of 108 recordings were watched 13 times (twice per behavior and once for NRS score) to score each variable. Once half of the video recordings were analyzed, the observer re-scored the first 10 videos of the trial and also re-scored 10 random videos from the expert to ensure that intra and inter-observer reliability levels were maintained.

\section{Statistical Analysis}

The data underwent analysis to find extreme outliers (3 times the interquartile range outside of the interquartile limits) using Excel, but no outliers were found. The residuals for each variable were examined to verify normality and homogeneity of variances. Only stride length, stance time, and swing time were found to follow a normal distribution. The number of steps taken, passage time, and time/step were transformed using a square root transformation. The normal and transformed variables were analyzed using the MIXED procedure of SAS (version 9.2, SAS Institute Inc., Cary, $\mathrm{NC}$ ). The differences between flooring types for these variables were tested using a generalized linear mixed model with cow as a random effect, week as a random block factor, and flooring type as a fixed effect. Multiple-comparisons with a Scheffé adjustment were done to analyze differences among flooring types. Hoof height, acceleration, asymmetry of variance acceleration, NRS, and behaviors associated with lameness were analyzed using a Kruskal-Wallis test with the NPAR1WAY procedure to find differences between flooring types. Any significance was reported at a probability of less than $5 \%$. Within each treatment, regression analyses were made between parity, DIM, and each variable to rule out any effect of these variables (Vasseur et al., 2012). All data presented are untransformed.

\section{RESULTS AND DISCUSSION}

\section{Kinematics in a Straight Configuration}

Cows walking on rubber showed an improvement in ease of movement compared with concrete as their stride length was $0.14 \mathrm{~m}$ longer on the rubber (Table 2 ). This is consistent with the previously reported longer stride length of nonlame cows on rubber compared with concrete (Telezhenko and Bergsten, 2005; Flower et al., 2007). Furthermore, the result obtained was within the range of 1.54 to $1.57 \mathrm{~m}$ previously reported for nonlame cows walking on rubber (Telezhenko and Bergsten, 2005; Flower et al., 2007). Stride length was respectively 0.11 and $0.17 \mathrm{~m}$ shorter on MMA 1 and 2 compared with rubber. On MMA 4, it did not differ from any other flooring, but it was longer on MMA 3 compared with MMA 2.

Table 2. Dairy cow ease of movement measured with kinematics, acceleration, gait and associated behaviors while walking on various flooring types in a straight configuration ${ }^{1}$

\begin{tabular}{|c|c|c|c|c|c|c|c|c|}
\hline Item & \multicolumn{6}{|c|}{ Flooring type ${ }^{2}$} & SEM & $P$-value \\
\hline Swing time, s & $0.65^{\mathrm{a}}$ & $0.63^{\mathrm{ab}}$ & $0.61^{\mathrm{b}}$ & $0.62^{\mathrm{ab}}$ & $0.63^{\mathrm{ab}}$ & $0.64^{\mathrm{ab}}$ & 0.010 & 0.0019 \\
\hline Stance time, $\mathrm{s}$ & $0.75^{\mathrm{b}}$ & $0.91^{\mathrm{ab}}$ & $0.82^{\mathrm{ab}}$ & $0.93^{\mathrm{a}}$ & $0.76^{\mathrm{b}}$ & $0.83^{\mathrm{ab}}$ & 0.057 & 0.0013 \\
\hline Hoof height, $\mathrm{m}$ & 0.06 & 0.06 & 0.07 & 0.06 & 0.06 & 0.06 & 0.004 & 0.6544 \\
\hline Asymmetry of variance acceleration, $\%$ & 22.70 & 42.44 & 22.56 & 30.17 & 29.43 & 32.78 & 6.964 & 0.0768 \\
\hline \multicolumn{9}{|c|}{ Locomotion and behaviors associated with lameness } \\
\hline Numerical rating system & 2.53 & 2.56 & 2.44 & 2.44 & 2.50 & 2.55 & 0.112 & 0.9095 \\
\hline Arch back & 1.08 & 1.14 & 1.17 & 1.10 & 1.09 & 1.11 & 0.221 & 0.9995 \\
\hline Head bob & 0.08 & 0.04 & 0.08 & 0.04 & 0.08 & 0.03 & 0.033 & 0.7721 \\
\hline Tracking up & 0.11 & 0.39 & 0.41 & 0.40 & 0.28 & 0.42 & 0.138 & 0.5563 \\
\hline Joint flexion & 1.39 & 1.32 & 1.33 & 1.36 & 1.37 & 1.34 & 0.041 & 0.8503 \\
\hline
\end{tabular}

\footnotetext{
${ }^{\mathrm{a}-\mathrm{c}}$ Least squares means within a row with different superscripts differ $(P<0.05)$.

${ }^{1}$ All data presented are untransformed.

${ }^{2}$ Flooring type: Rubber $=$ rubber mats; Concrete $=$ traction milled concrete; MMA $1=0.7-1.2$ mm quartz with 1 seal coat; MMA $2=0.7-1.2$ mm quartz with 2 seal coats; MMA $3=0.4-0.8 \mathrm{~mm}$ quartz with 1 seal coat; MMA $4=0.4-0.8 \mathrm{~mm}$ quartz with 2 seal coats.
} 
Swing time was $0.04 \mathrm{~s}$ shorter on MMA 1 than on rubber (Table 2), indicating a better ease of movement on rubber compared with MMA 1 (Flower et al., 2005, 2007). However, no differences were found between MMA 1 and any other flooring. Few researchers have looked at the effect of flooring surfaces on the swing time of cattle. Flower et al. (2007) compared the effect of flooring and hoof health on swing time and found that flooring differences were only apparent in cows with sole ulcers, which had a shorter swing time on concrete than on rubber. The values reported for swing time in the present study were outside the range of 0.42 to 0.57 s reported for healthy cows (Flower et al., 2005, 2007). Although cattle that have an impaired gait due to sole ulcers or lesions have been reported to have longer swing time, which may range between 0.55 to $0.57 \mathrm{~s}$ (Flower et al., 2005), the higher values in the present study may reflect differences in environment and animal factors, such as housing, herd management, or genetics, between experimental sites. In a study with sows, Conte et al. (2014) also observed herd differences in kinematic variables, which were independent of lameness scores.

Stance time on MMA 2 was 0.18 and 0.17 s longer than on rubber and MMA 3 (Table 2), respectively, but did not differ from any other flooring surfaces. Shorter stance time indicates a better ease of movement (Flower et al., 2005, 2007). This difference could potentially be explained by the fact that MMA 2 and 3 differed in both quartz size and number of seal coats. The MMA 2 had larger particle size and 2 seal coats, whereas MMA 3 had smaller particle size with only one seal coat. Because cows walking on MMA 3 showed improved stance duration compared with MMA 2, it is possible that cows were more at ease walking on a surface with smaller granulation, but with just enough seal coats to provide sufficient grip to walk at a steady pace. Once again, very few researchers have analyzed the effect of flooring type on stance time in cattle. Flower et al. (2007) reported no differences in stance time between cows walking on rubber and concrete flooring.

\section{Kinematics in a Right Angle Turn Configuration}

Rushen and de Passillé (2006) compared the number of steps taken by cattle walking on rubber and concrete flooring and found that cows took fewer steps on rubber compared with concrete (averages of 33.0 vs. 34.3 steps, respectively) indicating that they were more at ease walking on rubber. In our study, the number of steps on rubber was not significantly lower than on concrete. However, cows took more frequent steps on MMA 4 than on rubber (Table 3), indicating that they may have been less at ease walking on this surface, especially in a turn configuration. Differences between studies may be explained by the degree of difficulty of the experimental corridor. In Rushen and de Passillé (2006), cows had to walk on a corridor with one obstacle (gutter), in addition to a turn. This suggests that as the course becomes more challenging, cows are more at ease walking on rubber than on concrete.

The passage of a cow walking in a pathway should be short, with few steps taken and with short stride duration (Flower et al., 2005, 2007; Rushen and de Passillé, 2006). There were no differences in passage time among flooring types in the present study (Table 3), which does not support the shorter passage time for cows walking on rubber (23.2 s) compared with concrete (25.0 s) reported by Rushen and de Passillé (2006). These authors also found that cattle took on average 23.2 to $25.0 \mathrm{~s}$ to complete a $27 \mathrm{~m}$ course $(0.86$ to 0.93 $\mathrm{s} / \mathrm{m})$, whereas cows in the present study took on average 6.01 to $7.06 \mathrm{~s}$ to complete their $11.8 \mathrm{~m}$ course $(0.51$ to $0.60 \mathrm{~s} / \mathrm{m})$. Differences in speed between studies may

Table 3. Dairy cow ease of movement measured with number of steps, passage time, and acceleration while walking on various flooring types in a right-angle turn configuration ${ }^{1}$

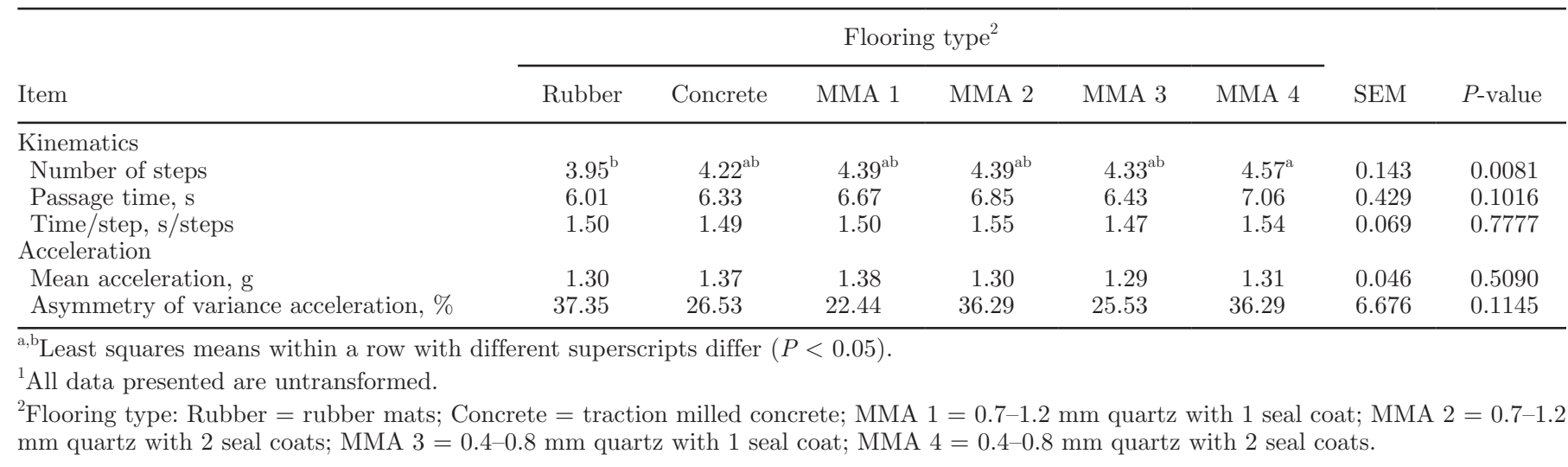


again be explained by the presence of an obstacle in the former study. Other studies investigated the speed $(\mathrm{m} / \mathrm{s})$ of cattle walking on rubber and concrete and found opposite results. For instance, Telezhenko and Bergsten (2005) found that cattle walking on rubber floors walked at a lower speed $(1.01 \mathrm{~m} / \mathrm{s})$ in comparison to concrete $(1.08 \mathrm{~m} / \mathrm{s})$. This was not supported by Flower et al. (2007) and Chapinal et al. (2011) who both found that cattle walking on rubber floors walked at a faster speed $(1.26$ and $1.28 \mathrm{~m} / \mathrm{s})$ than when walking on concrete $(1.21$ and $1.22 \mathrm{~m} / \mathrm{s})$.

No differences were found between flooring types in the time/step or stride duration (Table 3), which is consistent with the findings of Flower et al. (2007). Blackie et al. (2013) also reported no differences in stride duration between cattle with a gait score of 1 , 2, and 3. Flower et al. (2005) on the other hand found that cattle with sole ulcers had a longer stride duration than healthy cows (1.48 vs. $1.26 \mathrm{~s}$ ). These results suggest that stride duration is more susceptible to change with hoof health status than flooring type.

\section{Accelerometer Variables}

No differences between flooring types in any configuration were found for acceleration or asymmetry of variance (Tables 2 and 3). This is not consistent with the lower acceleration reported by Chapinal et al. (2011) on rubber in comparison to concrete (1.62 vs. $1.67 \mathrm{~g}$ ), which was explained by a greater absorption of the hoof impact by rubber. As for the asymmetry of variance, Chapinal et al. (2011) also found no differences in asymmetry of variance between cattle walking on rubber versus concrete, which is consistent with our results.

\section{Locomotion and Behaviors Associated with Lameness}

Healthy experimental animals that are not considered lame at the start of a trial may have a locomotion score of 2.4 to 2.5 on a total of 5 points (Flower et al., 2007), which matches the range obtained in the present study for NRS scores (Table 2). However, no differences were found between flooring types for NRS scores, which is not consistent with the improved locomotion scores reported by Flower et al. (2007) and Chapinal et al. (2011) for cows walking on rubber in comparison to concrete.

The lack of differences in arched back, reluctance to bear weight, and head bob between flooring types (Table 2) was expected because these variables only become apparent when cattle are moderately lame (score
$>3$; Flower and Weary, 2009). Flower et al. (2007) found that cattle suffering from sole ulcers had poor weight bearing (14 on a 100-unit scale) on all 4 limbs in comparison to cows without hoof issues (6.5 on a 100-unit scale), regardless of flooring type. This is an indicator that their hoof condition was painful enough to trigger a change in their weight distribution between limbs. However, because our cattle had low NRS and no sole ulcers, the flooring type they were walking on did not have any effect on their head movement, back posture, or weight distribution while walking.

Tracking up scores of healthy cattle may vary from 11 to 15 (scored with a 100-unit scale; Flower et al., 2007). Although we did not use the same scale as Flower et al. (2007), our cows also had very low scores (Table 2). No difference in tracking up was observed in the current study in contrast to the study by Flower et al. (2007), who reported that healthy cattle walking on rubber mats had better tracking up scores compared with concrete (11 vs. 15 on a 100-unit scale).

Joint flexion scores did not change with flooring type either (Table 2). Again, these results contrast with the reported improvements when cows walk on rubber $(23$ on a 100-unit scale) compared with concrete (27 on a 100-unit scale; Flower et al., 2007). The discrepancy between the 2 studies may be explained by the type of concrete used. Flower et al. (2007) tested their cows on smooth concrete, providing less traction than rubber. Phillips and Morris (2001) reported that cattle have better joint angulation on higher friction floors than on smooth surfaces. Based on different literature results, concrete may have a similar coefficient of friction as rubber (Table 1). However, concrete in the present experiment was traction milled, and because it was more texturized then regular grooved concrete, the friction was assumed to be greater than what is reported in Table 1. A study done by Franck et al. (2007) illustrated that flooring with greater texture tend to have a higher coefficient of friction. However, because the friction of the milled concrete was not measured and simply assumed to have a great friction, it is not possible to confirm if a higher coefficient of friction has an effect on joint flexion.

Finally, no differences between flooring types were found for asymmetric step scores (Table 2), which is consistent with the data obtained with the accelerometers. However, this contrasts with the reported improvement in symmetry on rubber (23 on a 100 -unit scale) in comparison to concrete (25 on a 100 -unit scale) (Flower et al., 2007). A similar improvement (5 points on a 100-unit scale) was also observed by Chapinal et al. (2011). Once again, it is possible that a more precise 100-unit scale was more suitable for the detection of differences between flooring types. 


\section{CONCLUSIONS}

Cows walking on rubber had longer stride length, suggesting better ease of movement, than when walking on traction milled concrete. However, rubber did not differ from concrete in any other measured variable. When comparing the MMA floorings to the controls, MMA 3 was consistently similar to rubber, whereas the other MMA floors showed an inconsistent resemblance to rubber. It should be noted that all 4 MMA floors did not differ from concrete in any of the ease of movement variables measured. These results suggest that MMA 3 may improve cow ease of movement, compared with the other MMA floors, but more research is required to confirm these findings.

\section{ACKNOWLEDGMENTS}

We thank Denis Simard, Serge Courchesne, and the barn staff at the (formerly) Alfred Campus Organic Dairy Research Center of the University of Guelph (Alfred, Ontario, Canada) for their contribution to animal care and handling. We also thank all the research assistants which have help made this project a success: Hugo Racine (Université de Sherbrooke, Sherbrooke, Quebec, Canada), Jean-Michel Beaudoin and Sabrina Plante (both from Université Laval, Quebec, Quebec, Canada), and Maureen O'Brien, Jessica St-John, and Elise Shepley (all 3 from University of Guelph, Guelph, Ontario, Canada); Tania Brunette for help with manuscript editing (McGill University, Ste-Anne-deBellevue, Quebec, Canada); and Dave Kelton for his comments and review of the manuscript (University of Guelph, Guelph, Ontario, Canada). This project was funded by the Government of Alberta and Agriculture and Agri-Food Canada through the Growing Forward Livestock Welfare Program within the Growing Forward 2 Initiative.

\section{REFERENCES}

Blackie, N., E. C. L. Bleach, J. R. Amory, and J. R. Scaife. 2013. Associations between locomotion score and kinematic measures in dairy cows with varying hoof lesion types. J. Dairy Sci. 96:3564-3572.

Booth, C. J., L. D. Warnick, Y. T. Grohn, D. O. Maizon, C. L. Guard, and D. Janssen. 2004. Effect of lameness on culling in dairy cows. J. Dairy Sci. 87:4115-4122.

Canadian Council on Animal Care. 2009. Guidelines on the care and use of farm animals in research, teaching and testing. CCAC, Ottawa, ON, Canada.

Cha, E., J. A. Hertl, D. Bar, and Y. T. Gröhn. 2010. The cost of different types of lameness in dairy cows calculated by dynamic programming. Prev. Vet. Med. 97:1-8.

Chapinal, N., A. K. Barrientos, M. A. G. von Kyserlingk, E. Galo, and D. M. Weary. 2013a. Herd- level risk factors for lameness in freestall farm in the northeastern United States and California. J. Dairy Sci. 96:318-328.
Chapinal, N., A. M. de Passillé, M. Pastell, L. Hanninen, L. Munksgaard, and J. Rushen. 2011. Measurement of acceleration while walking as an automated method for gait assessment in dairy cattle. J. Dairy Sci. 94:2895-2901.

Chapinal, N., A. M. de Passille, D. M. Weary, M. A. G. Von Keyserlingk, and J. Rushen. 2009. Using gait score, walking speed, and lying behavior to detect hoof lesions in dairy cows. J. Dairy Sci. 92:4365-4374.

Charlton, G. L., V. Bouffard, J. Gibbons, E. Vasseur, D. B. Haley, D. Pellerin, J. Rushen, and A. M. de Passillé. 2016. Can automated measures of lying time help assess lameness and leg lesions on tiestall dairy farms? Appl. Anim. Behav. Sci. 175:14-22.

Conte, S., R. Bergeron, H. Gonyou, J. Brown, F. C. Rioja-Lang, L. Connor, and N. Devillers. 2014. Measure and characterization of lameness in gestating sows using force plate, kinematic, and accelerometer methods. J. Anim. Sci. 92:5693-5703.

Cook, N. B., K. V. Nordlund, and G. R. Oetzel. 2004. Environmental influences on claw horn lesions associated with laminitis and subacute ruminal acidosis in dairy cows. J. Dairy Sci. 87(E. Suppl.):E36-E46.

de Passillé, A. M., M. B. Jensen, N. Chapinal, and J. Rushen. 2010. Technical note: Use of accelerometers to describe gait patterns in dairy calves. J. Dairy Sci. 93:3287-3293.

Enting, H., D. Kooij, A. A. Dijkhuizen, R. B. M. Huirne, and E. N. Noordhuizen-Stassen. 1997. Economic losses due to clinical lameness in dairy cattle. Livest. Prod. Sci. 49:259-267.

Espejo, L. A., M. I. Endres, and J. A. Salfer. 2006. Prevalence of lameness in high-producing Holstein cows housed in freestall barns in Minnesota. J. Dairy Sci. 89:3052-3058.

Flower, F. C., A. M. de Passillé, D. M. Weary, D. J. Sanderson, and J. Rushen. 2007. Softer, higher-friction flooring improves gait of cows with and without sole ulcers. J. Dairy Sci. 90:1235-1242.

Flower, F. C., D. J. Sanderson, and D. M. Weary. 2005. Hoof pathologies influence kinematic measures of dairy cow gait. J. Dairy Sci. 88:3166-3173.

Flower, F. C., and D. M. Weary. 2006. Effect of hoof pathologies on subjective assessments of dairy cow gait. J. Dairy Sci. 89:139-146.

Flower, F. C., and D. M. Weary. 2009. Gait assessment in dairy cattle. Animal 3:87-95.

Franck, A., G. Opsomer, A. De Kruif, and N. De Belie. 2007. Frictional interactions between bovine claw and concrete floor. Bios Eng. 96:565-580.

Georg, H. 2011. Skid resistance and durability of coated and uncoated concrete floors in dairy cattle. Pages 1-6 in 7th International Symposium on Cement Based Materials for a Sustainable Agriculture. Quebec, Canada.

Grandin, T., ed. 2010. Improving Animal Welfare: A Practical Approach. CABI, Boston, MA.

Greenough, P. R., and A. D. Weaver. 1997. Lameness in Cattle. 3rd ed. W.B. Saunders, Philadelphia, PA.

Grégoire, J., R. Bergeron, S. D. D'Allaire, M.-C. Meunier-Salaun, and N. Devillers. 2013. Assessment of lameness in sows using gait, footprints, postural behaviour and foot lesion analysis. Animal 7:1163-1173.

Hernandez-Mendo, O., M. A. G. Von Keyserlingk, D. M. Veira, and D. M. Weary. 2007. Effects of pasture on lameness in dairy cows. J. Dairy Sci. 90:1209-1214.

Hinterhofer, C., J. C. Ferguson, V. Apprich, H. Haider, and C. Stanek. 2006. Slatted floors and solid floors: Stress and strain on the bovine hoof capsule analyzed in finite element analysis. J. Dairy Sci. $89: 155-162$.

Ishler, V., D. Wolfgang, and D. Griswold. 1999. Prevention and control of foot problems in dairy cows. Department of Dairy and Animal Science and Department of Veterinary Science, College of Agricultural Sciences and Cooperative Extension. pp. 1-20.

Ito, K., M. A. G. von Keyserlingk, S. J. Leblanc, and D. M. Weary. 2010. Lying behavior as an indicator of lameness in dairy cows. J. Dairy Sci. 93:3553-3560.

Kossaibati, M. A., and R. J. Esslemont. 1997. The costs of production diseases in dairy herds in England. Vet. J. 154:41-51. 
Peake, K. A., A. M. Biggs, C. M. Argo, R. F. Smith, R. M. Christley, J. E. Routly, and H. Dobson. 2011. Effects of lameness, subclinical mastitis and loss of body condition on the reproductive performance of dairy cows. Vet. Rec. 168:301.

Penev, T., C. Mieva, V. Dimova, R. Roydev, J. Mitev, and A. Manolov. 2013. Assessing frictional properties of rubber floors in free housing systems for dairy cows. Trakia J. Sci. 2:197-204.

Phillips, C. J. C., B. Beerda, U. Knierim, S. Waiblinger, L. Lidfors, C C. Krohn, E. Canali, H. Valk, I. Veissier, and H. Hopster. 2013. A review of the impact of housing on dairy cow behaviour, health and welfare. Pages 37-54 in Livestock Housing: Modern Management to Ensure Optimal Health and Welfare of Farm Animals. A. Aland and T. Banhazi, ed. Wageningen Academic Publishers, Wageningen, the Netherlands.

Phillips, C. J. C., and I. D. Morris. 2000. The locomotion of dairy cows on concrete floors that are dry, wet, or covered with a slurry of excreta. J. Dairy Sci. 83:1767-1772.

Phillips, C. J. C., and I. D. Morris. 2001. The locomotion of dairy cows on floor surfaces with different frictional properties. J. Dairy Sci. 84:623-628.

Popescu, S., C. Borda, E. A. Diugan, M. Spinu, I. S. Groza, and C. D. Sandru. 2013. Dairy cows welfare quality in tie-stall housing system with or without access to exercise. Acta Vet. Scand. 55:43.

Rushen, J., and A. M. de Passillé. 2006. Effects of roughness and compressibility of flooring on cow locomotion. J. Dairy Sci. 89:29652972.

Rushen, J., and A. M. de Passillé. 2009. Flooring options to minimize lameness and optimize welfare. Advances in Dairy Technology: Proceeding of the Western Canadian Dairy Seminar. 21:293-301.
Solano, L., H. W. Barkema, E. A. Pajor, S. Mason, S. J. LeBlanc, J. C. Zaffino Heyerhoof, C. G. R. Nash, D. B. Haley, D. Pellerin, J. Rushen, A. M. de Passillé, E. Vasseur, and K. Orsel. 2015. Prevalence of lameness and associated risk factors in Canadian HolsteinFriesian cows housed in freestall barns. J. Dairy Sci. 98:6978-6991. Telezhenko, E., and C. Bergsten. 2005. Influence of floor type on the locomotion of dairy cows. Appl. Anim. Behav. Sci. 93:183-197.

USDA. 2009. Dairy 2007, Part V: Changes in dairy cattle health and management practices in the United States 1996-2007. \#519.0709. USDA: Animal and Plant Health Inspection Service: Veterinary Services, Center for Epidemiology and Animal Health, Fort Collins, CO.

van der Tol, P. P. J., J. H. M. Metz, E. N. Noordhuizen-Stassen, W. Back, C. R. Braam, and W. A. Weijs. 2005. Frictional forces required for unrestrained locomotion in dairy cattle. J. Dairy Sci $88: 615-624$.

Vasseur, E., J. Rushen, D. B. Haley, and A. M. de Passillé. 2012. Sampling cows to assess lying time for on-farm animal welfare assessment. J. Dairy Sci. 95:4968-4977.

Vermunt, J. J. 2007. One step closer to unravelling the pathophysiology of claw horn disruption: For the sake of the cows' welfare. Vet. J. $174: 219-220$

Warnick, L. D., D. Janssen, C. L. Guard, and Y. T. Grohn. 2001. The effect of lameness on milk production in dairy cows. J. Dairy Sci 84:1988-1997.

Weber, A., E. Stamer, W. Junge, and G. Thaller. 2013. Genetic parameters for lameness and claw and leg diseases in dairy cows. J. Dairy Sci. 96:3310-3318. 